\title{
Comparison of Post-operative Inflammatory Pattern between Intracameral Ceftazidime and Cefuroxime Used for the Prevention of Post-operative Endophthalmitis
}

\author{
Muhammad Moin, Arooj Amjad, Sameer Nagi
}

Pak J Ophthalmol 2019, Vol. 35, No. 3

See end of article for authors affiliations

Correspondence to:

Arooj Amjad,

Assistant Professor,

Postgraduate Medical Institute, Ameer ud Din Medical College, Lahore

Phone: +92-33344380677

Email: Arooj.amjad@gmail.com
Purpose: To compare the post operative inflammatory pattern after phacoemulsification in patients receiving intra-cameral injection of ceftazidime and cefuroxime per-operatively for the prevention of post-operative endophthalmitis.

Study Design: Quasi experimental study.

Place and Duration of Study: Ophthalmology Department Unit-1, Lahore General Hospital, Lahore from November 2016 to March 2018.

Material and Methods: Patients undergoing phacoemulsification with intraocular lens implantation were divided into 2 groups by convenient sampling. Group A received Cefuroxime and group B received Ceftazidime both as 1 $\mathrm{mg} / 0.1 \mathrm{ml}$ intra-cameral injections at the end of the routine surgery. The patients were examined pre and post operatively on slit lamp and the number of cells in the anterior chamber $(\mathrm{A} / \mathrm{C})$ were counted on first day, first week and 6 weeks after surgery.

Results: Out of 260 patients there were 130 in each group. On the first postoperative day in group $A$ there were grade 1 cells in A/C in 22 patients, grade 2 in 93 patients, grade 3 in 14 patients and Grade 4 in 1 patient. In group $B$ there were grade 1 cells in A/C in 11 patients, grade 2 in 96 patients, grade 3 in 20 patients and grade 4 in 3 patients. After one week, in group A, cell counts were grade 0 in 27 patients while in group B, cell counts were grade 0 in 23 patients. After 6 weeks no patient in any group showed any activity in the anterior chamber.

Conclusion: There is little difference in post operative inflammatory pattern of intracameral ceftazidime antibiotic prophylaxis as compared to intracameral cefuroxime.

Key Words: Endophthalmitis, Cataract Surgery, Cefuroxime, Ceftazidime.

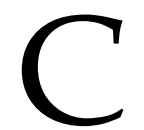

ataract is one of the most common causes of reversible blindness in the World and cataract surgery is one of the most commonly performed routine procedures by the ophthalmologists. Although there is a high success rate but still cataract surgery can lead to serious complications such as endophthalmitis, which is an inflammatory reaction that occurs as a result of intraocular colonization by microorganisms such as bacteria, fungi and rarely parasites. It can either be exogenous in type which can occur post-operatively or after trauma because of microbial contamination that spreads from the ocular surface or open wound or through contaminated instruments, intraocular 
implants such as lenses (IOLs) or intraocular foreign bodies or it can be endogenous (septicemia) in origin. Endophthalmitis has a poor visual outcome as shown by the European Society of Cataract and Refractive Surgeons (ESCRS) study where $17 \%$ of the patients had a final visual acuity $20 / 200$ or worse and $48.3 \%$ had a final visual acuity $20 / 40$ or worse ${ }^{1}$. Furthermore, if it is not treated it can progress and the inflammation can spread to other intraocular structures leading to great reduction in quality of life $^{2}$. It can cause complete loss of visual acuity and/or loss of the involved eye. According to the ESCRS study the patients undergoing cataract surgery using a clear corneal incision were more likely to develop postoperative endophthalmitis by 5.88 times as compared to those in which scleral incision was used although there were other risk factors such as old age and wound dehiscence ${ }^{3}$. There have been many methods described to prevent post-operative endophthalmitis. One of the most commonly used methods to prevent the infection was prophylactic instillation of 5\% povidone-iodine or topical antibiotic drops into the conjunctival sac per-operatively 4 . One study described that per-operative injection of antibiotics in the anterior chamber (intra-cameral) might be able to eliminate the bacteria that got access to the anterior chamber. In this regard, the antibiotics could either be given as continuous infusion during the surgery along with the irrigating BSS (basic salt solution) as a variable dose $^{5}$ or at the end of surgery as a fixed dose bolus injection. A UK based study compared the efficacy of subconjunctival antibiotic injection and intracameral antibiotic injection ${ }^{6}$ for the prevention of post-operative endophthalmitis concluding that the intracameral injections were more effective than subconjunctival injections. Many studies compared different antibiotics to be given as an intracameral injection at the end of surgery for the same purpose. In a retrospective study and some prospective trials, cephalosporins and vancomycin were studied extensively and evidence was provided on clinical efficacy of intracameral cephalosporins ${ }^{7}$. In this regard, the drug that proved to be very effective in reduction of the risk for acute onset of post-operative endophthalmitis was intracameral cefuroxime ${ }^{8}$. These studies however, did not compare the efficacy and safety of cephalosporins other than cefuroxime. This limitation was addressed by another study which compared cefuroxime, cefazolin and ceftazidime and their safety profiles for intracameral use ${ }^{9}$. Apparently, $1 \mathrm{mg}$ intracameral injection of cefuroxime effectively inhibited all the sensitive bacterial strains and therefore, it was associated with a low incidence of postoperative endophthalmitis. Cefuroxime was chosen on the basis of a Swedish study which comprised of a series of endophthalmitis cases from the year 1996 to the year 2000. Moreover, a thirdgeneration cephalosporin, ceftazidime was also used in Sweden following an epidemic that was caused by a Gram-negative bacterial strain. Another study showed the availability of intracameral antibiotics according to spectrum of activity, pharmacology, preparation, dosage as well as their safety and efficacy ${ }^{10}$.

The rationale of our study was to consider more alternatives to cefuroxime for the treatment of postoperative endophthalmitis. Although cefuroxime is used on regular basis, it has been less available in areas where it is not produced locally with pharmaceutical companies discontinuing its production abroad. Ceftazidime being its potential substitute could therefore be used. The purpose of this study was to compare the post operative inflammatory pattern after phacoemulsification in patients receiving intra-cameral injection of ceftazidime and cefuroxime per-operatively for the prevention of post-operative endophthalmitis.

\section{MATERIAL \& METHODS}

Patients undergoing cataract surgery in the Ophthalmology Department of Lahore General Hospital, Lahore were selected by convenient sampling to receive prophylactic intracameral injections of antibiotics towards the end of routine cataract surgery. The patients included in this study were adult patients who presented in Ophthalmology Department of Lahore General Hospital from November 2016 to March 2018. The patients with history of previous trauma, uveitis, corneal disease, glaucoma and complicated cataract were excluded from the study. Patients with only eye and/or those with history of endophthalmitis in the other eye were also not included. These patients were divided into two groups. In group $\mathrm{A}$, the patients received Cefuroxime whereas those in group $B$ received Ceftazidime both as $1 \mathrm{mg} / 0.1 \mathrm{ml}$ intracameral injections at the end of the surgery after wound hydration and before chamber formation. Approval was taken from the hospital Ethical Review Committee. The patients were examined pre and post operatively on slit lamp prior to pupillary dilatation on the slit lamp (Haag Streit, BQ 900). Post operative inflammation was graded according to the number of anterior chamber cells in a $1 \mathrm{~mm}$ by $1 \mathrm{~mm}$ slit beam 
field using 16 times magnification as anterior chamber cells are a dispensable indicator of inflammatory activity. This was done according to SUN (Standardization of Uveitis Nomenclature) working group grading of the anterior chamber cells ${ }^{11}$ as shown in table 1. Follow up examinations were done on day 1 , week 1 and week 6 after surgery. The data was recorded on an electronic medical database and later on analyzed by using SPSS 20.0. Comparison of the

Table 1: Grading of anterior chamber cells $(1 \mathrm{~mm}$ by 1 $\mathrm{mm}$ slit beam) according to SUN ${ }^{11}$.

\begin{tabular}{|ll|}
\hline Grade & Cells in field \\
\hline 0 & $<1$ \\
$1+$ & $6-15$ \\
$2+$ & $16-25$ \\
$3+$ & $26-50$ \\
$4+$ & $>50$ \\
\hline
\end{tabular}

two groups was done using Chi square test and $\mathrm{p}$ value equal to or less than 0.05 was taken as significant.

\section{RESULTS}

Out of total 260 patients, 130 were allocated to each group. The first post-operative day results showed mostly mild to moderate inflammation (grade 1 and 2) in both groups. After $1^{\text {st }}$ post operative week there was mostly none to mild inflammation (grade 0 and 1) in both groups. On last follow up at 6 weeks there was no inflammation (grade 0 ) in both groups (table 2).

While performing Pearson Chi square tests for independence on day 1 and week 1 the values were high on chi square test statistics (5.773 and 3.540) indicating that there is very little if no relationship between the antibiotics used (table 3). Furthermore, none of the patients developed endophthalmitis.

Table 2: Results on first day, first week and 6 weeks after surgery.

\begin{tabular}{|c|c|c|c|c|c|c|c|}
\hline \multirow{2}{*}{ Antibiotic } & \multicolumn{5}{|c|}{ Cells in Anterior Chamber 1st Day Post-op } & \multirow{2}{*}{ Total } & \multirow{2}{*}{ P value } \\
\hline & Grade 0 & Grade 1 & Grade 2 & Grade 3 & Grade 4 & & \\
\hline (Group A) Cefuroxime & 0 & $22(17 \%)$ & $93(71 \%)$ & $14(11 \%)$ & $1(1 \%)$ & 130 & \\
\hline (Group B) Ceftazidime & 0 & $11(8 \%)$ & $96(74 \%)$ & $20(16 \%)$ & $3(2 \%)$ & 130 & .123 \\
\hline \multirow[t]{3}{*}{ Total } & 0 & 33 & 189 & 34 & 4 & 260 & \\
\hline & \multicolumn{5}{|c|}{ Cells in Anterior Chamber $1^{\text {st }}$ Week Post-op } & Tata & $D_{\text {val }}$ \\
\hline & Grade 0 & Grade 1 & Grade 2 & Grade 3 & Grade 4 & 10 tal & P value \\
\hline (Group A) Cefuroxime & $27(21 \%)$ & $100(76.5 \%)$ & $2(1.5 \%)$ & $0(0 \%)$ & $1(1 \%)$ & 130 & \\
\hline (Group B) Ceftazidime & $23(18 \%)$ & $102(78.5 \%)$ & $3(2 \%)$ & $2(1.5 \%)$ & $0(0 \%)$ & 130 & .472 \\
\hline \multirow[t]{3}{*}{ Total } & 50 & 202 & 5 & 2 & 1 & 260 & \\
\hline & \multicolumn{5}{|c|}{ Cells in Anterior Chamber 6 week Post-op } & & \\
\hline & Grade 0 & Grade 1 & Grade 2 & Grade 3 & Grade 4 & Iotal & P value \\
\hline (Group A) Cefuroxime & $130(100 \%)$ & 0 & 0 & 0 & 0 & 130 & \\
\hline (Group B) Ceftazidime & $130(100 \%)$ & 0 & 0 & 0 & 0 & 130 & .472 \\
\hline Total & 260 & 0 & 0 & 0 & 0 & 260 & \\
\hline
\end{tabular}

Table 3: Statistical Analysis using Chi Square test for day 1 and week 1.

\begin{tabular}{|llcccccc|}
\hline Statistical Analysis & \multicolumn{3}{c}{ Analysis for Day 1 } & \multicolumn{3}{c|}{ Analysis for Week 1 } \\
& Value & Df & $\begin{array}{c}\text { Asymp. Sig. } \\
\text { (2-sided) }\end{array}$ & Value & Df & $\begin{array}{c}\text { Asymp. Sig. } \\
\text { (2-sided) }\end{array}$ \\
\hline Pearson Chi-Square & 5.773 & 3 & .123 & 3.540 & 4 & .472 \\
Likelihood Ratio & 5.896 & 3 & .117 & 4.700 & 4 & .319 \\
Linear by Linear Association & 5.313 & 1 & .021 & .000 & 1 & 1.00 \\
No. of Valid Cases & 260 & & & 260 & & \\
\hline
\end{tabular}




\section{DISCUSSION}

Post-operative endophthalmitis (POE) after cataract surgery is a dangerous and vision-threatening yet uncommon complication that is reported to occur at approximate rates ranging from $0.03 \%$ to $0.2 \%$. The most critical steps for minimizing the incidence of visual loss due to endophthalmitis are prompt diagnosis and early treatment. However, most recently all the efforts have been focused on the administration of antibiotics prophylactically so as to prevent the development of endophthalmitis ${ }^{12}$. For prevention of this serious complication many methods have been tried and tested from instillation of $5 \%$ povidone iodine in the eye pre-operatively to subconjunctival and intra-cameral antibiotic injections at the end of surgery. Among these methods, intracameral injection of cephalosporins has been under limelight for the past two decades. According to a survey conducted in Pakistan in 2005 only 1.87 percent of the consultants used intracameral antibiotic injections prophylactically for the prevention of post-operative endophthalmitis ${ }^{13}$. In our study, we have compared the efficacy of two commonly used intracameral cephalosporins; Cefuroxime and Ceftazidime. Due to non-availability of intracameral preparations of cephalosporins on a commercial level, we had to reconstitute the injection from the readily available powder form provided for either intravenous or intramuscular injections. For this purpose the manufacturers of these drugs recommended the use of distilled water. We used normal saline to reconstitute the solutions for intracameral use so as to avoid hypo-tonicity, as in the majority of clinical studies. Gupta et al used balanced salt solution as control ${ }^{14}$. Lockington et al however, gave a comparison of two protocols for dilution of cefuroxime injection ${ }^{13}$. They concluded that errors were bound to arise with usage of small (1cc) syringes. In our study, we used preparations that were reconstituted from 1 gram ceftazidime vials and 750 milligrams cefuroxime vials. We used $10 \mathrm{cc}$ syringes for this purpose, ensuring complete dissolution of the powdered drug and accuracy of dose. Errors in drug dilution and dose calculation may lead to increased risk of toxic anterior chamber syndrome. The reconstituted cephalosporin solutions were discarded after 4 hours of preparation so as to avoid any possible loss of efficacy. After all these measures, we injected intracameral cefuroxime in Group A patients and ceftazidime in Group B patients. We then measured cells in their anterior chambers on Day 1, week 1 and week 6 post-operatively. There was no statistically significant difference in the efficacy of both drugs. However, just like Barry et al this study only counted number of anterior chamber cells, not taking other diagnostic criteria for both acute and chronic endophthalmitis and other potential measurable features into account ${ }^{15}$. Also, in our study the absolute endothelial cell loss was not measured as Montan et al did in their study which was done on the safety of intracameral cefuroxime ${ }^{10}$.

Some large case series and randomized clinical trials showed the safety and efficacy of prophylactic use of intracameral cephalosporin injections for prevention of post-operative endophthalmitis following cataract surgery. According to the results from European Society of Cataract and Refractive Surgeons (ESCRS) multicenter randomized control trial which was done on 16,211 patients, the risk of development of endophthalmitis could be fairly reduced by 4.9 -fold with use of a prophylactic intracameral injection of cefuroxime ${ }^{16}$. Another analysis comparing the efficacy and safety of different antibiotic groups has shown that intracameral injections of Moxifloxacin and Cefuroxime reduce the rate of occurrence of endophthalmitis as compared to the controls with minimal or no toxicity events at the standard routine doses ${ }^{17}$. According to a ten year comparative study also, intracameral cefuroxime has proven to be very effective in reduction of risk for acute-onset endophthalmitis after cataract surgery ${ }^{18}$. Another study concluded that $1 \mathrm{mg}$ intracameral injection of cefuroxime apparently inhibited all the sensitive bacterial strains effectively and was also associated with a low incidence of postoperative endophthalmitis ${ }^{19}$. Seal et al concluded that the risk of contracting endophthalmitis after cataract removal by phacoemulsification was fivefold decreased by per-op intracameral injection of cefuroxime ${ }^{20}$. The $p$ values were given as 0.001 for presumed endophthalmitis and 0.005 for proven endophthalmitis. A German study also gave results that supported the significantly effective role of intracameral injection of cefuroxime in reduction of the rate of postoperative infectious endophthalmitis after cataract surgery ${ }^{21}$. The economic evaluation also compared many different prophylaxis regimens and drew the inference that intracameral cefuroxime has proved to be the best when it comes to cost-effectiveness ${ }^{22}$.

However, we needed an effective substitute of Cefuroxime because of its non-availability in areas where it is not produced locally with international pharmaceutical companies discontinuing distribution 
locally. Therefore, in our study we compared the effect of intracameral cefuroxime injection with intracameral ceftazidime injection and found that both produced similar post operative inflammatory patterns and endophthalmitis was not seen in any patient. A randomized control trial on the safety of intracameral cephalosporins concluded that ceftazidime, cefuroxime and cefazolin all could be safely used as 1 $\mathrm{mg}$ in $0.1 \mathrm{~mL}$ prophylactic intracameral injection during cataract surgery towards the end. In this series, 55 out of 59 strains of microbial pathogens that were isolated were found sensitive to cefuroxime9. According to a recent study, the evidence to support intracameral cefuroxime use for reduction in the rate of acute post-operative endophthalmitis after cataract surgery is not strong enough. There is however, a marginal benefit that might be considered to justify its use $^{23}$. More recently there have been debates about the use of intracameral antibiotic prophylaxis in every patient undergoing cataract surgery on routine basis ${ }^{24}$.

The limitation of our study was that it was done at one center only and the sample size was small. To get more generalizable results in the population larger multicenter study needs to be done. If substantiated by a further research involving many centers our study may provide further rationale for the use of ceftazidime as compared to cefuroxime.

\section{CONCLUSION}

In summary, we demonstrate that there is no significant statistical difference between the post operative inflammatory patterns of both the treatments. They both prevent endophthamitis and there is little if any difference in ceftazidime antibiotic prophylaxis compared to the current cefuroxime regimen used in the patients. This, in turn, can further aid and help in the evaluation of the safety and effectiveness of the two antibiotics above and beyond just prevention of a post-operative complication.

\section{Financial Disclosure}

No author has a financial or proprietary interest in any material or method mentioned.

\section{Conflict of Interest}

None.

\section{REFERENCES}

1. Barry P, Gardner S, Seal D, Gettinby G, Lees F, Peterson $\mathbf{M}$ et al. Clinical observations associated with proven and unproven cases in the ESCRS study of prophylaxis of postoperative endophthalmitis after cataract surgery. J Cataract Refract Surgery, 2009; 35 (9): 1523-1531.e1. doi: 10.1016/j.jcrs.2009.03.049. PubMed PMID: 19683148.

2. Clark A, Ng J, Morlet N, Tropiano E, Mahendran P, Spilsbury K et al. Quality of life after postoperative endophthalmitis. Clin Exp Ophthalmol, 2008; 36 (6): 526-531. J Cataract Refract Surg. 2009 Sep;35(9):1523-31, 1531.e1. Doi: 10.1016/j.jcrs.2009.03.049. PubMed PMID: 19683148.

3. Wejde G, Samolov B, Seregard S, Koranyi G, Montan P. Risk factors for endophthalmitis following cataract surgery: a retrospective case-control study. J Hosp Infec, 2005; 61 (3): 251-256.

4. Ciulla TA, Starr MB, Masket S. Bacterial endophthalmitis prophylaxis for cataract surgery: an evidence-based update. Ophthalmology, 2002; 109 (1): 13-24.

5. Sobaci G, Tuncer K, Taş A, Özyurt M, Bayer A, Kutlu $\mathbf{U}$. The effect of intraoperative antibiotics in irrigating solutions on aqueous humor contamination and endophthalmitis after phacoemulsification surgery. Eur J Ophthalmol. 2003; 13 (9-10): 773-778.

6. Yu-Wai-Man P, Morgan SJ, Hildreth AJ, Steel DH, Allen D. Efficacy of intracameral and subconjunctival cefuroxime in preventing endophthalmitis after cataract surgery. J Cat Refract Surg, 2008; 34 (3): 447-451. doi: 10.1016/j.jcrs.2007.10.041.

7. Romero P, Méndez I, Salvat M, Fernández J, Almena M. Intracameral cefazolin as prophylaxis against endophthalmitis in cataract surgery. J Cataract Refract Surg. 2006; 32 (3): 438-441.

8. García-Sáenz MC, Arias-Puente A, RodrígeuzCaravaca G, Bañuelos JB. Effectiveness of intracameral cefuroxime in preventing endophthalmitis after cataract surgery: ten-year comparative study. J Cataract Refract Surg. 2010; 36 (2): 203-207.

9. Lam PT, Young AL, Cheng LL, Tam PM, Lee VY. Randomized controlled trial on the safety of intracameral cephalosporins in cataract surgery. Clin Ophthalmol. 2010; 4: 1499-1504.

10. Braga-Mele $\mathbf{R}$, Chang DF, Henderson BA, Mamalis N, Talley-Rostov A, Vasavada A. Intracameral antibiotics: Safety, efficacy, and preparation. J Cataract Refract Surg. 2014 Dec; 40 (12): 2134-42.

11. Trusko B1, Thorne J, Jabs D, Belfort R, Dick A, Gangaputra S, Nussenblatt R, Okada A, Rosenbaum J. The Standardization of Uveitis Nomenclature (SUN) Project. Development of a clinical evidence base utilizing informatics tools and techniques. Methods Inf Med. 2013; 52 (3): 259-265.

12. George NK, Stewart MW. The Routine Use of Intracameral Antibiotics to Prevent Endophthalmitis 
after Cataract Surgery: How Good is the Evidence Ophthalmol Ther. 2018 Dec; 7 (2): 233-245.

13. Ashraf KM, Siddique M. Endophthalmitis prophylaxis for cataract surgery: The first Pakistan survey. J Cataract Refract Surg. 2006; 32 (2): 368.

14. Gupta MS, McKee HDR, Saldaña M, Stewart OG. Macular thickness after cataract surgery with intracameral cefuroxime. J Cataract Refract Surg. 2005; 31 (6): 1163-1166.

15. Barry P, Behrens-Baumann $W$, Pleyer U, Seal D. ESCRS Guidelines on prevention, investigation and management of post-operative endophthalmitis. European Society for Cataract \& Refractive Surgeons, 2007: 2 .

16. Endophthalmitis Study Group, European Society of Cataract and Refractive Surgeons. Prophylaxis of postoperative endophthalmitis following cataract surgery: results of the ESCRS multicenter study and identification of risk factors. J Cataract Refract Surg. 2007; 33 (6): 978-988.

17. Bowen RC, Zhou AX, Bondalapati S, Lawyer TW, Snow KB, Evans PR et al. Comparative analysis of the safety and efficacy of intracameral cefuroxime, moxifloxacin and vancomycin at the end of cataract surgery: a meta-analysis.Br J Ophthalmol. 2018 Sep; 102 (9): 1268-1276.

18. García-Sáenz MC, Arias-Puente A, RodríguezCaravaca G, Bañuelos JB. Effectiveness of intracameral cefuroxime in preventing endophthalmitis after cataract surgery: Ten-year comparative study. J Cataract Refract

\author{
Author's Affiliation \\ Prof. Muhammad Moin \\ Professor of Ophthalmology \\ Postgraduate Medical Institute \\ Ameer-ud-Din Medical College \\ Lahore General Hospital, Lahore \\ Dr. Arooj Amjad \\ Assistant Professor Ophthalmology \\ Postgraduate Medical Institute \\ Ameer ud Din Medical College \\ Lahore General Hospital, Lahore \\ Sameer Nagi \\ Elective Student \\ Lahore General Hospital, Lahore \\ Final Year Medical Student \\ St. Georges Hospital, London, UK
}

Surg, 2010; 36 (2): 203-7.

19. Montan PG, Wejde G, Koranyi G, Rylander M. Prophylactic intracameral cefuroxime: Efficacy in preventing endophthalmitis after cataract surgery. Journal of Cataract Refract Surg, 2002; 28 (6): 977-81.

20. Seal DV, Barry P, Gettinby G, Lees F, Peterson M, Revie CW et al. ESCRS study of prophylaxis of postoperative endophthalmitis after cataract surgery: Case for a European multi-centre study. J Cataract Refract Surg. 2006; 32: 396-406.

21. Röck T, Bramkamp M, Bartz-Schmidt KU, Mutlu U, Yörük E, Röck D et al. Using intracameral cefuroxime reduces postoperative endophthalmitis rate: 5 year experience at the University Eye Hospital Tübingen. Klin Monbl Augenheilkd. 2014 Oct; 231 (10): 1023-1028.

22. Linertová $\mathbf{R}$, Abreu-González $\mathbf{R}$, García-Pérez $\mathbf{L}$, Alonso-Plasencia $M$, Cordovés-Dorta LM, AbreuReyes JA et al. Intracameral cefuroxime and moxifloxacin used as endophthalmitis prophylaxis after cataract surgery: systematic review of effectiveness and cost-effectiveness. Clin Ophthalmol. 2014 Aug 14; 8: 1515-22. Doi:10.2147/OPTH.S59776.

23. Sharma S, Sahu SK, Dhillon V, Das S, Rath S. Reevaluating intracameral cefuroxime as a prophylaxis against endophthalmitis after cataract surgery in India. J Cataract Refract Surg. 2015 Feb; 41 (2): 393-9.

24. Grzybowski A. Has the Time Come for All to Routinely Use Intracameral Antibiotic Prophylaxis at the Time of Cataract Surgery? Am J Ophthalmol. 2016 Sep; 169: 293294.

\section{Author's Contribution}

Prof. Muhammad Moin

Study design, Data collection, Critical review.

Dr. Arooj Amjad

Manuscript writing and Data analysis.

Sameer Nagi

Statistical analysis and Manuscript writing. 